\title{
Prolactin stimulates integrin-mediated adhesion of circulating mononuclear cells to endothelial cells
}

\author{
Pável Montes de Oca, Yazmín Macotela, Gabriel Nava, Fernando López-Barrera, \\ Gonzalo Martínez de la Escalera and Carmen Clapp
}

Instituto de Neurobiología, Universidad Nacional Autónoma de México, Campus UNAM-Juriquilla, Queretaro, Qro, Mexico

\begin{abstract}
Attachment of leukocytes to endothelial cells is an essential step for the extravasation and recruitment of cells at sites of inflammation. The pituitary hormone prolactin (PRL) is involved in the inflammatory process. Here, we show that treatment with PRL of human peripheral blood mononuclear cells (PBMC) stimulates their adhesion to human umbilical vein endothelial cells (HUVEC) activated by interleukin-1 $\beta$. Stimulation of adhesion by PRL is mediated via integrins leukocyte functional antigen-1 (LFA-1) and very late antigen-4 (VLA4), because immunoneutralization of both integrins prevents PRL action. Also, PRL promotes the adhesion of PBMC to immobilized intercellular adhesion molecule-1 and fibronectin, ligands for LFA-1 and VLA-4, respectively. Stimulation of integrin-mediated cell adhesion by PRL may involve the activation of chemokine receptors, because PRL upregulates the expression of the G-protein-coupled chemokine receptor CXCR3 in PBMC, and pertussis toxin, a specific G-protein inhibitor, blocks PRL stimulation of PBMC adhesion to HUVEC. In addition, PRL stimulates tyrosine phosphorylation pathways leading to leukocyte adhesion. PRL triggered the tyrosine phosphorylation of Janus kinase-2, of signal transducer and activator of transcription-3 and 5, and of the focal adhesion protein paxillin. Furthermore, genistein, a tyrosine kinase inhibitor, blocked PRLstimulated adhesion of PBMC and Jurkat T-cells to HUVEC. These results suggest that PRL promotes integrinmediated leukocyte adhesion to endothelial cells via chemokine receptors and tyrosine phosphorylation signaling pathways.

Laboratory Investigation (2005) 85, 633-642, advance online publication, 7 March 2005; doi:10.1038/labinvest.3700256
\end{abstract}

Keywords: adhesion; chemokine receptors; endothelial cells; integrins; peripheral blood mononuclear cells; peptide hormones; tyrosine phosphorylation

Extravasation of leukocytes plays a central role in inflammatory and immune responses and is regulated by various signaling and adhesion molecules. ${ }^{1,2}$ Integrin-dependent adhesion of leukocytes to endothelial cells provides firm attachment and mediates transendothelial leukocyte migration. Chemokines produced in the local microenvironment stimulate the binding of integrins on leukocytes to their counter-ligands, which are expressed on endothelial cells and are upregulated by proinflammatory cytokines. ${ }^{1,2}$

Prolactin (PRL), the hormone originally associated with milk production, is secreted by lymphocytes ${ }^{3-6}$

Correspondence: Dr C Clapp, PhD, Instituto de Neurobiología, Universidad Nacional Autónoma de México, Campus UNAMJuriquilla, Km 15 Carretera Qro-SLP, Querétaro, Qro., 76230, Mexico

E-mail: clapp@servidor.unam.mx

Received 20 November 2004; revised 14 January 2005; accepted 18 January 2005; published online 7 March 2005 and has stimulatory effects on the immune system. ${ }^{3-11}$ The presence of PRL receptors on immunocytes ${ }^{6}$ is consistent with PRL stimulation of $\mathrm{T}$ cells, B cells, natural killer cells, macrophages, neutrophils, CD34 + hematopoietic cells, and antigen-presenting dendritic cells. ${ }^{3-11}$ Animals with targeted disruption of either the PRL ${ }^{12,13}$ or the PRL receptor ${ }^{14}$ gene suggest that PRL is not essential for normal immune system development or function. However, PRL can be important for immune system homeostasis in autoimmune diseases and in stressful conditions including trauma, infection, and inflammation. ${ }^{15,16}$

The role of female hormones in immune system homeostasis is supported by the well-established observations that many autoimmune diseases occur more frequently in women than in men, ${ }^{17}$ and that depression of immune functions following conditions of severe stress is lower in females than in males. ${ }^{18}$ In this regard, the circulating levels of PRL are higher in females and elevated in patients with 
systemic lupus erythematosus, multiple sclerosis, rheumatoid arthritis, psoriatic arthritis, and in patients prior to transplant rejection. ${ }^{11,19-22}$ Moreover, PRL can protect against the suppression of immune functions under severe stress. For example, administration of PRL after trauma-induced hemorrhage improves macrophage and splenocyte functions, ${ }^{23,24}$ reduces plasma corticosterone levels, and decreases the mortality from subsequent sepsis. ${ }^{24}$ In addition, the PRL receptor is upregulated in the thymus during acute phase response induced by LPS $;{ }^{25}$ PRL protects against bacterial infections, ${ }^{26,27}$ and exposure to PRL can result in inflammatory responses characterized by infiltration of lymphocytes, macrophages, and neutrophils. ${ }^{28-30}$ The immunoenhancing properties of PRL may also include stimulation of leukocyte adhesion. PRL induces the expression of intracellular adhesion molecule (ICAM)-1 in the corpus luteum in association with enhancing the local accumulation of monocytes/ macrophages. ${ }^{29}$ Furthermore, PRL receptors belong to the hematopoietic cytokine receptor superfamily, characterized by its ability to activate the Janus kinase/signal transducer and activator of transcription (JAK/STAT) signal transduction pathway. ${ }^{6}$ This pathway can be functionally linked to the focal adhesion kinase (FAK)/paxillin pathway involved in integrin-mediated cell adhesion and migration. ${ }^{31,32}$ In fact, PRL activates JAK-2/STAT-5 and induces tyrosine phosphorylation of FAK and of paxillin in breast carcinoma cells. ${ }^{31}$ Moreover, growth hormone, which is structurally related to PRL and has receptors belonging to the same superfamily, ${ }^{6}$ stimulates neutrophil adhesion through tyrosine phosphorylation of JAK-2, STAT3 , FAK, and paxillin. ${ }^{32}$

This study was undertaken to investigate whether PRL stimulates integrin-mediated adhesion of leukocytes to endothelial cells. Herein, we demonstrate that PRL promotes the adhesion of peripheral blood mononuclear cells (PBMC) to human umbilical vein endothelial cells (HUVEC), and that this stimulation is mediated by the integrins leukocyte functional antigen-1 (LFA-1) (also known as CD11a/CD18) and very late antigen-4 (VLA-4) (or CD49d/CD29). Furthermore, we show that PRL up-regulates the expression of the chemokine receptor CXCR3 involved in the selective recruitment of $\mathrm{T}$ cells ${ }^{33}$ and enhances tyrosine phosphorylation of paxillin in the Jurkat human T-leukemic cell line. These results reveal previously unrecognized proinflammatory actions of PRL.

\section{Materials and methods}

\section{Antibodies and Reagents}

Human recombinant PRL produced in C127 cells was from Genzyme Corporation (Framingham, MA, USA), whereas human recombinant PRL generated in Escherichia coli was from Joseph A Martial
(University of Liege, Sart Tilman, Belgium). Cell culture media and reagents and human plasma fibronectin (FN) was obtained from Gibco-BRL (Gathersburg, MD, USA). Polymixin-B and pertussis toxin were from SIGMA Chemicals (St Louis, MO, USA). $\mathrm{Na}^{51} \mathrm{CrO}_{4}$ was from Amersham Life Science (Buckinghamshire, UK). Soluble recombinant human ICAM-1, anti-LFA-1 (BCA1), and anti-VLA-4 (BBA37) mAb were from R\&D Systems (Minneapolis, MN, USA). Anti-phosphotyrosine (4G10) and anti-paxillin (5H11) mAb were from Upstate Biotechnology (Lake Placid, NY, USA) and polyclonal Ab anti-Jak2, anti-STAT-3 and anti-STAT-5 were from Santa Cruz Biotechnology (Santa Cruz, CA, USA). Genistein was from Calbiochem (San Diego, CA, USA).

\section{Cell Isolation and Culture}

PBMC were isolated from healthy, nonsmoker, male volunteers (aged 20-45 years) using a density gradient of Histopaque-1077 (Sigma Chemicals) according to the manufacturer's instructions. Cells were washed in PBS, resuspended at a final concentration of $10^{6}$ cells $/ \mathrm{ml}$ in RPMI-1640 medium (Gibco-BRL) supplemented with $2 \mathrm{mM}$ of L-glutamine, antibiotics and 10\% FBS. PBMC were cultured for up to 3 days in the presence or absence of PRL (50-200 ng/ml) with or without polymixin B $(10 \mu \mathrm{g} / \mathrm{ml})$. For the $5 \mathrm{~min}$ to $1 \mathrm{~h}$ incubations, cells were resuspended in culture medium without serum. HUVEC were obtained from the umbilical vein and cultured on FN-coated dishes $\left(1 \mu \mathrm{g} / \mathrm{cm}^{2}\right)$ as described elsewhere. ${ }^{34}$ Jurkat cells (American Type Culture Collection, Rockville, MD, USA) were cultured in RPMI-1640 supplemented with $2 \mathrm{mM}$ L-glutamine, $1 \%$ penicillin-streptomycin, $10 \% \mathrm{FBS}$, $1 \%$ nonessential amino acids, and $1 \%$ sodium pyruvate. Jurkat cells were seeded at $2 \times 10^{5}$ cells/ $\mathrm{ml}$ and the medium was changed every $48 \mathrm{~h}$.

\section{Adhesion of PBMC to HUVEC}

The adhesion method used was based on that described by Shimizu et al. ${ }^{35}$ HUVEC (passages 36 ) were plated at $4 \times 10^{4}$ cells per well in FN-coated 96-well plates and cultured for $48 \mathrm{~h}$ or until confluent. HUVEC were activated with $10 \mathrm{ng} / \mathrm{ml}$ of IL-1 $\beta$ for $4 \mathrm{~h}$, washed and placed in assay medium (RPMI-1640 with $20 \mathrm{mM}$ HEPES) immediately prior to the beginning of the experiment. PBMC were labeled for $1 \mathrm{~h}$ at $37^{\circ} \mathrm{C}$ with ${ }^{51} \mathrm{Cr}\left(35 \mu \mathrm{Ci}\right.$ per $5 \times 10^{6}$ cells) before short-term (5-30 min) PRL treatment or after ending treatment with PRL for $1-72 \mathrm{~h}$. The labeled PBMC were resuspended in assay medium, and added $\left(5 \times 10^{4}\right.$ cells per well) to quintuplicate wells of endothelial cells in a final volume of $100 \mu \mathrm{l}$. PBMC and HUVEC were coincubated for $1 \mathrm{~h}$ at $37^{\circ} \mathrm{C}$ with or without blocking mAb anti-LFA-1 and antiVLA $-4 \mathrm{mAb}$ at a saturating concentration of $10 \mu \mathrm{g} / \mathrm{ml}$. In other experiments, PBMC treated or not with PRL 
for $72 \mathrm{~h}$ were incubated in the presence or absence of pertussis toxin ( $1 \mathrm{mM})$ for $2 \mathrm{~h}$, washed and labeled with ${ }^{51} \mathrm{Cr}$ before coincubation with IL-1 $\beta$-activated HUVEC. In addition, PBMC or Jurkat cells were labeled with ${ }^{51} \mathrm{Cr}$ and then incubated in the presence or absence of genistein $(10 \mu \mathrm{M})$ for $30 \mathrm{~min}$, followed by a 30-min incubation with or without PRL, before coincubation with activated HUVEC. After coincubation, wells were washed twice by immersion in $37^{\circ} \mathrm{C}$ Dulbecco's PBS (D-PBS) containing 1\% BSA, followed by flicking to remove nonadherent cells. HUVEC and bound PBMC were lysed with 1\% Triton X-100 in assay medium, and $\gamma$-emissions were counted. Bound radioactivity was expressed as percentage of the total radioactivity of the PBMC added. The increase ratio is the ratio of the bound values in the treated sample to that in the untreated control.

\section{Adhesion of PBMC to Immobilized FN or ICAM-1}

Adhesion of PBMC to FN or ICAM-1 was evaluated as described previously. ${ }^{36}$ Briefly, microtiter plates (Immulon II, Dynex Technologies, Chantilly, VA, USA) were coated for $1 \mathrm{~h}$ at room temperature with $50 \mu \mathrm{l}$ of FN $(100 \mu \mathrm{g} / \mathrm{ml})$ or $50 \mu \mathrm{l}$ of ICAM-1 $(10 \mu \mathrm{g} / \mathrm{ml})$ dissolved in D-PBS. The remaining protein-binding sites on the plastic surface were blocked by incubation for $1 \mathrm{~h}$ at room temperature with $10 \%$ BSA in D-PBS. Plates were washed 3 times by immersion in D-PBS. PBMC treated or untreated with PRL were added $\left(5 \times 10^{4}\right.$ cells/well $)$ to quintuplicate $\mathrm{FN}$ - or ICAM-1-coated wells in a final volume of $100 \mu \mathrm{l}$. Cells were incubated for $30 \mathrm{~min}$ on ice and subsequently for $45 \mathrm{~min}$ at $37^{\circ} \mathrm{C}$ on a rotating platform. After incubation, wells were washed 3 times by immersion in D-PBS containing $10 \%$ BSA at $37^{\circ} \mathrm{C}$ to remove non-adherent cells. Bound cells were fixed with $4 \%$ paraformaldehyde in PBS for $10 \mathrm{~min}$ and stained with $0.1 \%$ toluidine blue. Adhesion was evaluated by counting bound cells in five microscope fields per well using the Image-Pro Plus software (Media Cybernetics, Silver Springs, MD, USA). Results were normalized against untreated controls and are expressed as the increase ratio.

\section{Reverse Transcription-Polymerase Chain Reaction}

Total RNA was extracted from PBMC using Trizol (Invitrogen Corporation, Carlsbad, CA, USA) and treated with RNase-free DNase for $15 \mathrm{~min}$ at $37^{\circ} \mathrm{C}$ followed by phenol-chloroform extraction. Reverse transcription was performed using $5 \mu \mathrm{g}$ of total RNA, $10 \mu \mathrm{M}$ oligo(dT) ${ }_{16}$ primers, and MMLV retrotranscriptase (Invitrogen Corporation) at $37^{\circ} \mathrm{C}$ for 60 min. For CXCR1 detection, forward and reverse primers were $5^{\prime}$-TCCTGGGAAATGACACAGCA- ${ }^{\prime}$ and $5^{\prime}$-AAGCCAAAGGTGTGAGGCAG-3', respectively. For CXCR2, forward primer 5'-TTCCGAAG GACCGTCTACTCA-3' and reverse primer $5^{\prime}$ -
AGTTTGCTGTATTGTTGCCCATG-3' were used. For CXCR3, forward and reverse primers were $5^{\prime}$ AACTGTGGCCGAGAAAGCAG- $3^{\prime}$ and $5^{\prime}$-GCAGTG CATCTAGCCCAGG-3', respectively. mRNA for ribosomal protein L19 (RPL19) was amplified as internal control using as forward and reverse primers $5^{\prime}$-CGAAATCGCCAATGCCAACTC- $3^{\prime}$ and 5'-TGCTCCATGAGAATCCGCTTG-3', respectively. For I-TAC forward primer was 5'-GGTTACCATCG GAGTTTACAAAG-3 $3^{\prime}$ and reverse primer was $5^{\prime}-$ AAGTGTGTATTTGCATGAAAAAATGT- $3^{\prime}$; for $\gamma$ interferon-inducible 10-kDa protein (IP-10) forward primer was 5'-AGGGGAGCAAAATCGATGCAGT-3' and reverse primer was $5^{\prime}$-CATCCACTAAGAACA TAGCACCT-3'; and for MIG forward primer was $5^{\prime}-$ CATATGCTCTGAATTTATCTGAGTC- ${ }^{\prime}$ and reverse primer 5'-AAAATTATTAAAACCTAGTTCCACAG-3'. Conventional PCR was performed as described ${ }^{37}$ using 35 cycles for CXCR and CXC ligand amplification and 21 cycles for the RPL19 internal control. Using RPL-19 as internal standard, real-time PCR was carried out as indicated ${ }^{37}$ in reactions that contained $1 \mu \mathrm{l}$ aliquots of the reverse transcription reaction described above, $7.5 \mu \mathrm{l}$ of Quantitec SYBR Green PCR (Qiagen, Hilden, Germany) and $400 \mathrm{nM}$ forward and reverse primers in $15 \mu \mathrm{l}$ total volume. Detection and data analysis were carried out on a LightCycler Instrument according to the manufacturer's instructions (Roche Molecular Biochemicals, Mannheim, Germany).

\section{Immunoprecipitation and Western Blot}

To investigate the tyrosine-phosphorylation of JAK-2, STAT-3, STAT-5, and paxillin, Jurkat cells $\left(10 \times 10^{6}\right)$ were stimulated with PRL (50-500 ng/ml) for $30 \mathrm{~min}$ at $37^{\circ} \mathrm{C}$. Immunoprecipitation and Western blot analyses were performed as described elsewhere. ${ }^{32}$ Briefly, cells were lysed in $100 \mu \mathrm{l}$ ice-cold lysis buffer $(50 \mathrm{mM}$ Tris pH $7.4,0.5 \%$ NP-40, $0.2 \%$ sodium deoxycholate, $100 \mathrm{mM} \mathrm{NaCl}, 1 \mathrm{mM}$ EGTA, $1 \mathrm{mM}$ PMSF, $1 \mu \mathrm{g} / \mathrm{ml}$ aprotinin, $1 \mathrm{mM}$ sodium orthovanadate, and $1 \mathrm{mM} \mathrm{NaF}$ ), and centrifuged (15 000 r.p.m.) at $4^{\circ} \mathrm{C}$ for $30 \mathrm{~min}$ to separate the insoluble fraction. Lysates were incubated overnight with $4 \mu \mathrm{g} / \mathrm{ml}$ of anti-JAK-2, anti-STAT-3, anti-STAT-5, or anti-paxillin. Next, $20 \mu \mathrm{l}$ of protein-A beads were added and the immunoprecipitated proteins were resolved on $12 \%$ SDS-PAGE. Membranes were probed with anti-phosphotyrosine $\mathrm{mAb}(0.5 \mu \mathrm{g} / \mathrm{ml})$ and then reprobed with the respective $\mathrm{mAb}(1 \mu \mathrm{g} / \mathrm{ml})$ to determine amounts of the proteins loaded on the gel.

\section{Data Analysis}

All results were replicated in three or more independent experiments. PBMC were from at least three different donors. Data are expressed as the mean \pm s.e.m. As appropriate, Student's unpaired $t$-test or one-way ANOVA followed by Tukey's test to 
compare individual means was used for statistical comparisons. The significance level was set at $5 \%$.

\section{Results}

\section{PRL Increases PBMC Adhesion to HUVEC}

Freshly isolated PBMC were treated with PRL for up to $72 \mathrm{~h}$ and incubated for $1 \mathrm{~h}$ with HUVEC activated by pretreatment with IL-1 $\beta$ for $4 \mathrm{~h}$. PRL stimulated the adhesion of PBMC to HUVEC as early as $5 \mathrm{~min}$ after treatment (Table 1). Maximal adherence was observed at $1 \mathrm{~h}$ and was maintained thereafter. PBMC adhesion showed a bell-shaped response to treatment with increasing concentrations of recombinant PRL for $1 \mathrm{~h}$ (Figure 1a) or $72 \mathrm{~h}$ (Figure 1b). Peak stimulation was observed at $50 \mathrm{ng} / \mathrm{ml}$ and produced a 60 and $67 \%$ increase of adhesion to HUVEC after 1 and $72 \mathrm{~h}$ of PRL treatment, respectively. Similar dose-response curves were obtained

Table 1 Effect of PRL on PBMC adhesion to HUVEC ${ }^{a}$

\begin{tabular}{|c|c|c|c|c|c|c|c|}
\hline & \multicolumn{7}{|c|}{ Time } \\
\hline & $5 \mathrm{~min}$ & $15 \mathrm{~min}$ & $30 \mathrm{~min}$ & $1 \mathrm{~h}$ & $6 h$ & $18 \mathrm{~h}$ & $72 \mathrm{~h}$ \\
\hline Control & $20.6 \pm 0.67$ & $21.5 \pm 0.95$ & $19.7 \pm 1.2$ & $17.2 \pm 0.81$ & $14.3 \pm 0.62$ & $12.5 \pm 0.47$ & $9.2 \pm 0.76$ \\
\hline PRL (50 ng/ml) & $27.5 \pm 0.82^{*}$ & $30.3 \pm 0.86$ * & $27.3 \pm 0.62 *$ & $28.2 \pm 1.33^{*}$ & $22.5 \pm 1.5^{*}$ & $19.4 \pm 1.71$ * & $15.4 \pm 1.24^{*}$ \\
\hline Increase ratio & 1.33 & 1.41 & 1.39 & 1.64 & 1.57 & 1.55 & 1.67 \\
\hline
\end{tabular}

${ }^{\mathrm{a}}$ Values are bound radioactivity expressed as percentage of the total radioactivity in plated PBMC. Increase in ratio represents the change in the normalized values. PBMC were treated with PRL $(50 \mathrm{ng} / \mathrm{ml})$ according to the indicated time interval at $37^{\circ} \mathrm{C}$. PBMC were then labeled with ${ }^{51} \mathrm{Cr}$ and incubated with IL-1 $\beta$-activated HUVEC for $1 \mathrm{~h}$. Nonadherent cells were washed and total radioactivity per well counted. Results are presented as the mean \pm s.e.m. of three separate experiments.

${ }^{*} P<0.05$ vs untreated cells.
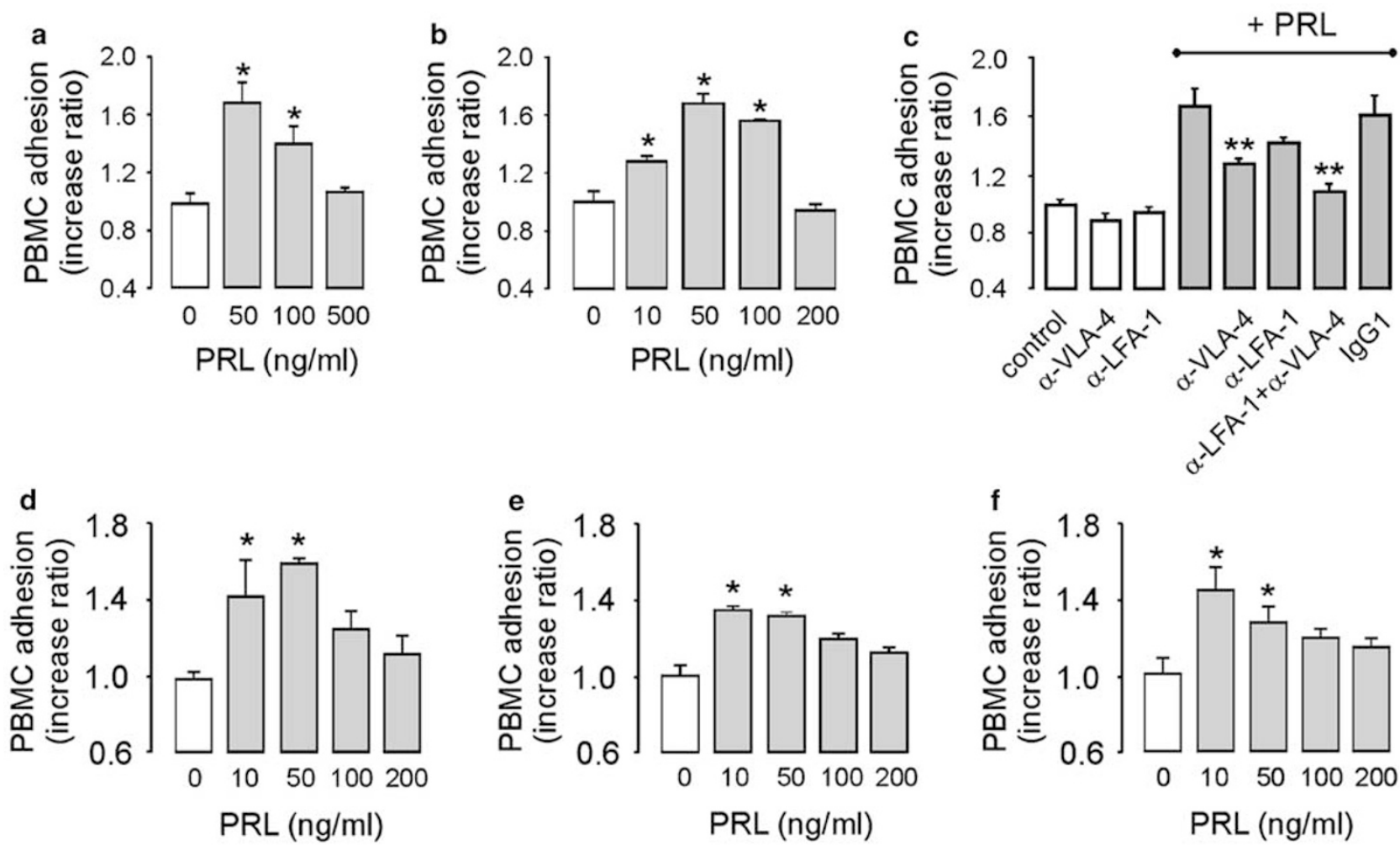

Figure 1 PRL stimulates the adhesion of PBMC to HUVEC through integrins VLA-4 and LFA-1. Dose-dependent effect of a $1 \mathrm{~h}$ (a) or $72 \mathrm{~h}$ (b) treatment with PRL on the adhesion of PBMC to HUVEC. PBMC were incubated with medium alone or with the indicated concentration of PRL and coincubated with IL-1 $\beta$-activated HUVEC. (c) Inhibitory effect of anti-LFA-1 and anti-VLA-4 mAb on PRLinduced PBMC adhesion to HUVEC. PBMC were treated for $72 \mathrm{~h}$ with or without PRL $(50 \mathrm{ng} / \mathrm{ml})$ in the absence or presence of $10 \mu \mathrm{g} / \mathrm{ml}$ of each $\mathrm{mAb}$ alone or in combination or with control Ab (IgG1). (d,e) Dose-dependent effect of incubating with PRL for $72 \mathrm{~h}$ on the adhesion of PBMC to immobilized ICAM-1 (d) or FN (e). (f) PRL-induced adhesion to FN was evaluated in the presence or absence of polymixin-B $(10 \mu \mathrm{g} / \mathrm{ml})$. The increase ratio is the ratio of the bound values in the treated sample to that in the untreated control. Results are the means \pm s.e.m. of three independent experiments. ${ }^{*} P<0.05$ vs nontreated control. ${ }^{*} P<0.05$ vs PBMC treated with PRL in the absence of mAb. 
with recombinant PRL generated in C127 cells (Figure 1) or in E. coli (data not shown). In all the following experiments, C127 recombinant PRL was used.

\section{LFA-1 and VLA-4 Integrins Mediate PRL Stimulation} of PBMC Adhesion to HUVEC

To determine whether integrins VLA-4 and LFA-1 mediate PRL stimulation of adhesion, the effect of function-blocking mAb to VLA-4 and LFA-1 was tested upon the 72-h PRL stimulation of PBMC adhesion to HUVEC (Figure 1c). Anti-VLA-4 mAb reduced PRL-induced adhesion by 58\% $(P<0.05)$, while anti-LFA-1 mAb produced a smaller nonsignificant inhibition. However, the combined use of both anti-VLA-4 and anti-LFA-1 mAb inhibited PRL stimulation by $83 \%$. In addition, PRL stimulated the adhesion of PBMC to immobilized ICAM-1 or FN, ligands of VLA-4 and LFA-1, respectively. In these experiments, PBMC treated with PRL for $72 \mathrm{~h}$ were incubated for $1 \mathrm{~h}$ with the purified, immobilized ligands. PRL stimulated PBMC adhesion in a bellshaped dose-response fashion, with maximal increases of 60 and $40 \%$ for ICAM-1 (Figure 1d) and FN (Figure 1e), respectively.

Because bacterial LPS are a widespread contaminant, and are known to stimulate leukocyte adhesion to endothelial cells and extracellular matrix proteins, ${ }^{2}$ we ascertained the effect of PRL in the presence of polymixin B, an inhibitor of LPS activity. Polymixin B did not interfere with PRLinduced stimulation of PBMC adhesion to FN (Figure 1f). This finding is consistent with activity displayed by PRL from different sources (C127 cells and E. coli) and suggests that PRL alone is an effective stimulator of leukocyte adhesion.

\section{PRL Induces the Expression of the Chemokine Receptor CXCR3 in PBMC}

To study the putative contribution of chemokine receptor pathways to PRL-induced stimulation of PBMC adhesion, we investigated the effects of PRL on the expression of chemokine receptors CXCR3, CXCR2 and CXCR1, which selectively bind chemokines sharing the CXC arrangement of their first two cysteine residues. Total RNA from PBMC incubated with or without PRL for $72 \mathrm{~h}$ was subjected to reverse transcription-polymerase chain reaction (RT-PCR). Amplification yielded products with the expected lengths for CXCR3 (68 bp), CXCR2 (73 bp), and CXCR1 (64 bp). The expression of the CXCR3 transcript was barely detected without PRL and markedly induced by PRL treatment (Figure 2a). PRL induced CXCR3 mRNA by 2.5-fold when evaluated by real-time PCR (Figure 2b). In contrast, the expression of CXCR2 and CXCR1 transcripts was similar in the presence or absence of PRL (Figure 2a). In addition, when carried out in HUVEC using primers for CXC chemokines, RT-PCR amplified products with the expected lengths for ITAC (263 bp), IP-10 (295 bp), and MIG (335 bp) (Figure 2c), suggesting that HUVEC express the three known ligands of CXCR3. Finally, pertussis toxin, a G-protein inhibitor, blocked PRL stimulation of PBMC adhesion to HUVEC (Figure 2d), further suggesting the contribution of the G-protein coupled receptor CXCR3 to PRL-induced adhesion.
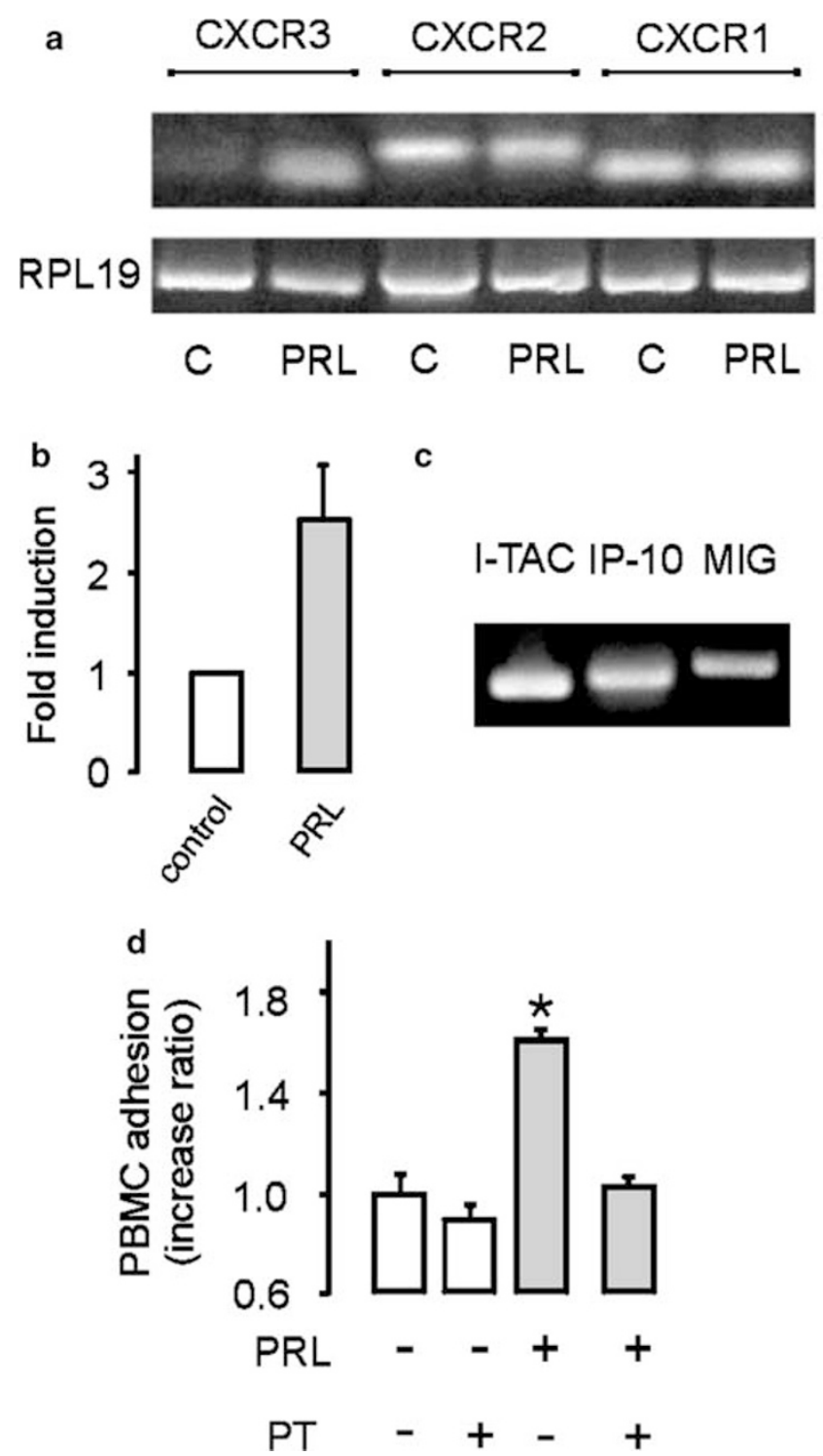

Figure 2 PRL induces the expression of chemokine receptor CXCR3 in PBMC. (a) mRNAs for chemokine receptors: CXCR3, CXCR2, and CXCR1 were analyzed by RT-PCR performed on total RNA extracted from PBMC incubated for $72 \mathrm{~h}$ in the presence or absence of PRL ( $50 \mathrm{ng} / \mathrm{ml}$ ). Amplification of RPL-19 is shown as control. (b) Quantitation of CXCR3 mRNA expression using realtime PCR. (c) mRNAs for the CXCR3 ligands I-TAC, IP-10, and MIG were analyzed by RT-PCR in HUVEC. (d) Inhibitory effect of pertussis toxin on PRL-induced adhesion of PBMC to HUVEC. PBMC treated or not with PRL for $72 \mathrm{~h}$ were incubated in the presence or absence of pertussis toxin $(1 \mathrm{mM})$ for $2 \mathrm{~h}$ before coincubation with HUVEC. Results are means \pm s.e.m. ${ }^{*} P \leq 0.05$ vs nontreated control. 
C
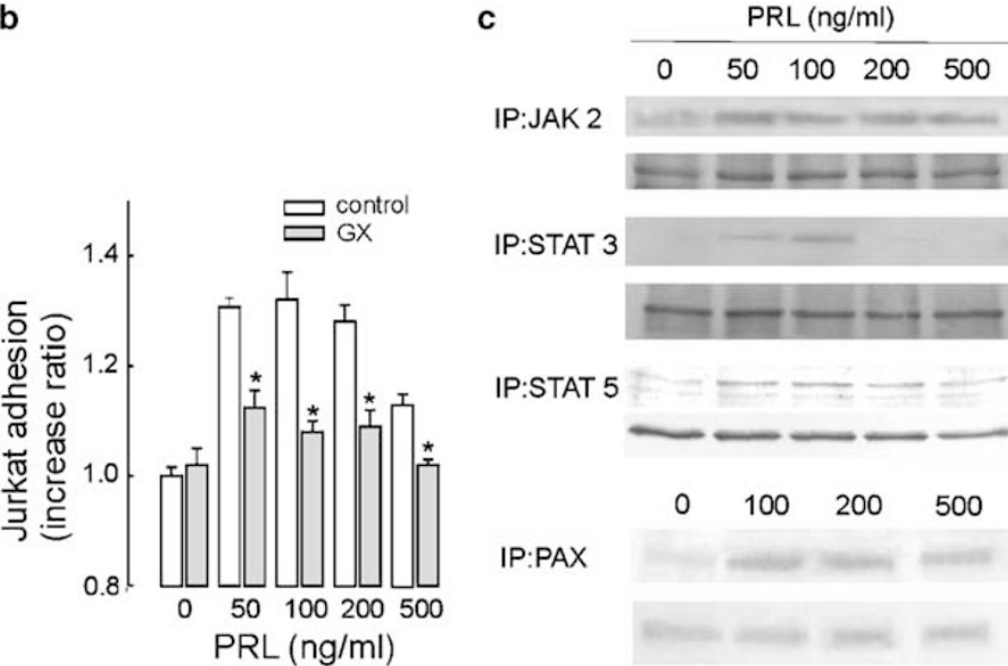

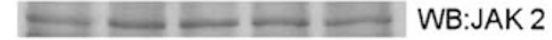

WB:PY

IP:STAT 3 WB:PY

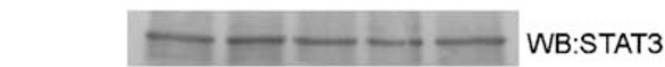

IP:STAT $5=-\cdots$ WB:PY

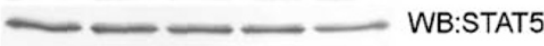

IP:PAX

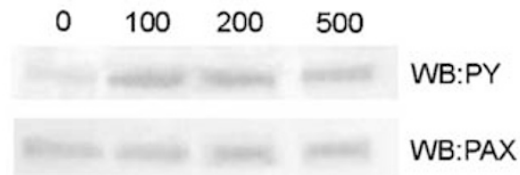

Figure 3 PRL stimulates adhesion through tyrosine phosphorylation pathways. Inhibitory effect of genistein on the PRL-induced adhesion of PBMC (a) or Jurkat cells (b) to HUVEC. Cells were incubated in the presence or absence of genistein (10 $\mu \mathrm{M})$ for $30 \mathrm{~min}$, followed by a 30-min incubation with or without increasing concentrations of PRL before coincubation with HUVEC. Results are means \pm s.e.m. ${ }^{*} P \leq 0.05$ vs nontreated control at the same PRL concentration. (c) PRL induces tyrosine phosphorylation of JAK-2, STAT3 , STAT-5, and paxillin (PAX) in Jurkat cells. Jurkat cells were treated with the indicated concentrations of PRL for 30 min and cell lysates immunoprecipitated (IP) with Ab anti-JAK-2, STAT-3, STAT-5, or PAX. Subsequently Western blots (WB) were probed with antiphosphotyrosine mAb or with Ab anti-JAK-2, STAT-3, STAT-5, or PAX as described in Materials and methods.

\section{PRL Stimulates Adhesion Through Tyrosine Phosphorylation Pathways}

We also tested whether tyrosine-phosphorylation pathways may contribute to the PRL effect on adhesion by using genistein, a typical tyrosine kinase inhibitor. In these experiments, PBMC or the Jurkat T-cell line were incubated with genistein for $30 \mathrm{~min}$ and then with or without PRL for $30 \mathrm{~min}$. Subsequently, all cells were incubated with activated HUVEC for $1 \mathrm{~h}$. Consistent with previous findings, treatment with PRL for $30 \mathrm{~min}$ stimulated the adhesion of PBMC and Jurkat cells to HUVEC in a bell-shaped dose-dependent fashion. Genistein blocked the effect of PRL in both PBMC and Jurkat cells (Figure 3a,b). Next, the effect of PRL on tyrosine phosphorylation of JAK-2, STAT-3, STAT5 , and paxillin was investigated. Jurkat cells were incubated with different concentrations of PRL for $30 \mathrm{~min}$ and subjected to immunoprecipitation-Western blot. Initial blotting with antiphosphotyrosine antibodies showed that PRL induced the tyrosine phosphorylation of JAK-2, STAT-3, STAT-5, and paxillin (Figure 3c). Subsequent blotting with the respective antibodies demonstrated that equal amounts of these proteins were loaded in each lane.

\section{Discussion}

Extensive evidence supports the stimulatory role of PRL in the immune-hematopoietic system, ${ }^{3-11}$ and although an absolute requirement for PRL in immune function has been questioned, ${ }^{12-14}$ new interest has been raised by evidence showing that PRL can counteract the effects of negative immuno- regulatory factors in autoimmune diseases and in stressful conditions. ${ }^{15,16,38,39}$ Here, we report that PRL promotes the adhesion of leukocytes to vascular endothelium, a previously unrecognized action that may contribute to the immunoenhancing properties of this hormone during immune-inflammatory processes.

The results of this study indicate that PRL rapidly augments the adhesion of PBMC to IL- $1 \beta$-activated HUVEC and that this effect is sustained for many hours. Maximal stimulation (67\%) is lower than the reported increase $(220 \%)$ in the adhesion of splenocytes to HUVEC induced by IL-2, ${ }^{40}$ but higher than the increase (32\%) in neutrophil adhesion induced by growth hormone, ${ }^{32}$ a PRL-related hormone with well-known immune functions. ${ }^{41}$ Similar to the effect of growth hormone on cell adhesion, ${ }^{32}$ the dose-response curve of PRL on leukocyte adhesion was 'bell-shaped.' Such a shape is a common observation for PRL stimulation of the PRL receptor, ${ }^{4}$ and it has been explained on the basis that signal transduction by PRL requires binding of one PRL molecule to two receptor molecules. ${ }^{42}$ At high concentrations, PRL can saturate the receptor and hinder receptor dimerization.

While this is the first report of PRL acting directly on leukocytes to stimulate their adhesion to vascular endothelium, the ability of PRL to recruit immune cells has been reported previously. In vivo studies have shown that PRL stimulates the accumulation of mononuclear cells in the prostate during inflammatory reactions, ${ }^{28}$ in the pleural cavity after carrageenan injection, ${ }^{30}$ and in the corpus luteum during regression. ${ }^{29}$ Also, PRL stimulates the expression of ICAM-1 in the corpus luteum, ${ }^{29}$ and 
in vitro studies showed that PRL promotes the chemotactic capacity of macrophages. ${ }^{43}$

Stimulation of cell adhesion by PRL may involve the activation of integrins LFA-1 and VLA-4, major molecular pathways that mediate firm attachment of leukocytes to vascular endothelium. ${ }^{1,2}$ Circulating leukocytes constitutively express LFA-1 and VLA-4 in a low-affinity state. However, after leukocyte activation, the affinity of both integrins is enhanced, enabling binding to their counter-ligands on endothelial cells, that is, ICAM-1 and ICAM-2 for LFA-1, and vascular cell adhesion molecule-1 (VCAM-1) for VLA-4. ${ }^{1,2}$ Consistent with LFA-1 and VLA-4 being crucial determinants in PRL-stimulated adhesion, the combination of mAbs against both LFA-1 and VLA-4 blocked PRL-induced adhesion of PBMC to HUVEC, and PRL stimulated the adhesion of PBMC to immobilized ICAM-1 and FN.

To analyze how PRL becomes functionally linked to integrin-mediated adhesion, we investigated the possible association of PRL with chemokine receptor pathways. Chemokines constitute a large family of chemotactic cytokines that are present at or near the endothelial cell surface and act by binding to $G$ protein-coupled receptors on leukocytes to promote their integrin-mediated adhesion to endothelial cells. The CXC chemokine subfamily selectively activates receptors CXCR1 to CXCR6. ${ }^{44}$ As reported for various leukocyte subtypes, ${ }^{45}$ PBMC constitutively expressed the mRNA for CXCR1, CXCR2, and CXCR3; however, treatment with PRL resulted in the induction of CXCR3 but not of CXCR1 or CXCR2. CXCR3 is upregulated by IL-2 in T lymphocytes, ${ }^{46}$ IL-2 promotes T-cell adhesion to vascular endothelium, ${ }^{40}$ and it has been claimed that CXCR3 plays a major role in T-cell recruitment. ${ }^{33}$ Also, the CXCR3 ligands IP-10, I-TAC, and MIG are upregulated in endothelial cells by IFN- $\gamma^{47}$ and CXCR3 appears to be their only receptor on T cells. ${ }^{33,48}$ Therefore, $\mathrm{T}$ cells are likely targets for PRL-induced CXCR3 expression.

Upregulation of CXCR3 in T cells is a potential mechanism by which PRL could promote the adhesion of PBMC to vascular endothelium. Nearly, $70 \%$ of PBMC cells are $\mathrm{T}$ cells, and activation of CXCR3 promotes the transendothelial migration of T cells via the LFA-1 and VLA-4 pathways. ${ }^{49}$ Also, HUVEC express the mRNAs for IP-10, I-TAC, and $\mathrm{MIG},{ }^{47}$ and therefore can produce CXCR3 ligands in culture. More importantly, we found that the effect of PRL on PBMC adhesion to HUVEC was blocked by treatment with pertussis toxin, an inhibitor G-protein coupled receptors. Because all known chemokine receptors are coupled to G-proteins, ${ }^{33}$ this result does not imply that CXCR3 is the only chemokine receptor mediating PRL stimulation of cell adhesion, only that chemokine receptors are likely to be involved.

G-protein coupled receptors elicit the rapid activation of integrins by complex mechanisms that involve regulation of the affinity of integrins via conformational changes of integrin chains and regulation of the avidity of integrins by increasing lateral mobility and clustering. Signaling occurs through different types of second messengers including small GTPases of the RAS family (RAP1, RAPL, RHOA), cytoskeletal proteins (talin, paxillin), protein serine kinases (atypical protein kinase- $\zeta$, phosphoinositide-3-kinase), and protein tyrosine kinases, ${ }^{50,51}$ etc.

While de novo protein synthesis of chemokine receptors may participate in the stimulation of leukocyte adhesion by PRL, a shorter-term mechanism may operate as well since PRL stimulates the adhesion of PBMC to HUVEC as early as 5 min after treatment. The PRL receptor signals through the JAK/STAT pathway, and activation of this pathway by PRL can be functionally linked to the increased tyrosine phosphorylation of paxillin. ${ }^{31}$ Paxillin is a signaling adaptor protein that binds to the cytoplasmic tails of integrins and is important for coordinating the formation of focal adhesions leading to integrin-mediated cell adhesion and motility. ${ }^{52,53}$ For example, tyrosine phosphorylation of paxillin stimulates LFA-1-dependent migration by promoting the activation of Pyk2 and FAK. ${ }^{50}$

The present study demonstrates that treatment with PRL for 30 min triggers the tyrosine phosphorylation of JAK-2, STAT-3, STAT-5, and paxillin in the Jurkat-T human leukemic cell line, a PRL target cell. ${ }^{54}$ This finding is consistent with extensive evidence showing that PRL stimulates tyrosine phosphorylation of JAK-2, STAT-3, and STAT5 in other cell types. ${ }^{5,6,55}$ Although PRL-induced tyrosine phosphorylation of JAK-2, STAT-5, paxillin, and FAK has been reported in breast cancer cells, ${ }^{31}$ this is the first study showing the activation of the JAK/STAT/paxillin pathway in immune cells. The molecular mechanism(s) linking the JAK/STAT pathway to the activation of the FAK/paxillin pathway remain largely unknown, but it has been proposed that STATs can function as intracellular adaptors in coupling the two pathways. ${ }^{32}$ STAT-3 is physically associated with JAK-2 and FAK in neutrophils, and the fact that growth hormone stimulates this association appears to contribute to the activation of the JAK-2/STAT-3/FAK/paxillin pathway by growth hormone. ${ }^{32}$ Finally, the possibility that PRL-induced leukocyte adhesion to endothelial cells is related to the tyrosine phosphorylation of these signaling molecules is suggested by the fact that genistein inhibits PRL-stimulated adhesion of Jurkat cells and PBMC to HUVEC. This observation is consistent with the previous report showing that growth hormonemediated tyrosine phosphorylation of the JAK-2/ STAT-3/FAK/paxillin pathway is inhibited by genistein, which also blocks the adhesion of neutrophils. ${ }^{32}$

The fact that PRL stimulates adhesion of leukocytes to vascular endothelium is consistent with its proposed role of enhancing inflammatory responses. ${ }^{11,15}$ Fluctuations in the circulating levels 
of PRL could stimulate immune function by this and other mechanisms. A wide range of stressors stimulate the release of PRL by the anterior pituitary gland, ${ }^{4,38,56}$ and some results indicate that PRL can counteract the negative effects of steroids or other suppressive agents also released by stress. ${ }^{16,38,39}$ In addition, it has been suggested that hyperprolactinemia during pregnancy and lactation can contribute to the adaptations required for immunological acceptance of the fetus and protection of the maternal immune system against general suppression. ${ }^{16}$ Finally, increased levels of PRL are associated with aggravated autoimmune diseases, whereas inhibition of PRL release by bromocriptine ameliorates autoimmunity progression. ${ }^{11,19-21}$ Owing to its sexually dimorphic characteristics, PRL actions on the immune system may contribute to the distinct immune environment that determines the female preponderance of autoimmune diseases such as multiple sclerosis, rheumatoid arthritis, and systemic lupus erythematosus. ${ }^{17}$

On the other hand, leukocyte adhesion may be stimulated not only by circulating PRL but also by the locally produced hormone. PRL is synthesized by various cells of the immune system, ${ }^{4}$ including $\mathrm{PBMC}^{57}$ and by endothelial cells from different blood vessels, ${ }^{58,59}$ including HUVEC. ${ }^{34}$ The putative contribution of locally produced PRL implies that the immunoenhancing properties of the hormone may not depend on changes in its circulating levels, but on specific regulatory mechanisms, that adjust PRL expression locally.

In summary, this work reports for the first time that PRL acts on circulating immune cells to stimulate their integrin-mediated adhesion to vascular endothelium. Elucidation of the precise cellular and molecular mechanisms by which PRL promotes leukocyte adhesion and the signaling pathways involved should be relevant for understanding the role of this hormone in inflammatory responses. This knowledge may help clarify gender differences in autoimmunity and could lead to the discovery of improved therapies for autoimmune diseases.

\section{Acknowledgements}

We thank A Prado, D Mondragón, P Galarza, M Garcia, and A Lara for their expert technical assistance and DD Pless for editing the manuscript. This work was supported by National Autonomous University of Mexico Grant IN227502 and the National Council of Science and Technology of Mexico Grants 36041-N and 43401.

\section{References}

1 Springer TA. Traffic signals for lymphocyte recirculation and leukocyte emigration: the multistep paradigm. Cell 1994;76:301-314.
2 Ebnet K, Kaldjian EP, Anderson AO, et al. Orchestrated information transfer underlying leukocyte endothelial interactions. Annu Rev Immunol 1996;14:155-177.

3 Matera L. Endocrine, paracrine and autocrine actions of prolactin on immune cells. Life Sci 1996;59: 599-614.

4 Ben-Jonathan N, Mershon JL, Allen DL, et al. Extrapituitary prolactin: distribution, regulation, functions, and clinical aspects. Endocr Rev 1996;17:639-669.

$5 \mathrm{Yu}$-Lee LY. Molecular actions of prolactin in the immune system. Proc Soc Exp Biol Med 1997;215: 35-52.

6 Bole-Feysot C, Goffin V, Edery M, et al. Prolactin (PRL) and its receptor: actions, signal transduction pathways and phenotypes observed in PRL receptor knockout mice. Endocr Rev 1998;19:225-268.

7 Dogusan Z, Hooghe R, Verdood P, et al. Cytokine-like effects of prolactin in human mononuclear and polymorphonuclear leukocytes. J Neuroimmunol 2001;120: 58-66.

8 Kooijman R, Hooghe-Peters EL, Hooghe R. Prolactin, growth hormone, and insulin-like growth factor-I in the immune system. Adv Immunol 1996;63:377-454.

9 Matera L, Mori M, Galetto A. Effect of prolactin on the antigen presenting function of monocyte-derived dendritic cells. Lupus 2001;10:728-734.

10 Buckley AR. Prolactin, a lymphocyte growth and survival factor. Lupus 2001;10:684-690.

11 Matera L, Mori M, Geuna M, et al. Prolactin in autoimmunity and antitumor defense. J Neuroimmunol 2000;109:47-55.

12 Foster MP, Jensen ER, Montecino-Rodriguez E, et al. Humoral and cell-mediated immunity in mice with genetic deficiencies of prolactin, growth hormone, insulin-like growth factor-I, and thyroid hormone. Clin Immunol 2000;96:140-149.

13 Dorshkind K, Horseman ND. The roles of prolactin, growth hormone, insulin-like growth factor-I, and thyroid hormones in lymphocyte development and function: insights from genetic models of hormone and hormone receptor deficiency. Endocr Rev 2000;21: 292-312.

14 Bouchard B, Ormandy CJ, Di Santo JP, et al. Immune system development and function in prolactin receptor-deficient mice. J Immunol 1999;163:576-582.

$15 \mathrm{Yu}$-Lee LY. Prolactin modulation of immune and inflammatory responses. Recent Prog Horm Res 2002;57: 435-455.

16 Dorshkind K, Horseman ND. Anterior pituitary hormones, stress, and immune system homeostasis. Bioessays 2001;23:288-294.

17 Whitacre CC. Sex differences in autoimmune disease. Nat Immunol 2001;2:777-780.

18 Wichmann MW, Zellweger R, DeMaso CM, et al. Enhanced immune responses in females, as opposed to decreased responses in males following haemorrhagic shock and resuscitation. Cytokine 1996;8:853-863.

19 Walker SE, McMurray RW, Houri JM, et al. Effects of prolactin in stimulating disease activity in systemic lupus erythematosus. Ann NY Acad Sci 1998;840: 762-772.

20 McMurray RW. Estrogen, prolactin, and autoimmunity: actions and interactions. Int Immunopharmacol 2001;1:995-1008.

21 Velkeniers B, Dogusan Z, Naessens F, et al. Prolactin, growth hormone and the immune system in humans. Cell Mol Life Sci 1998;54:1102-1108. 
22 Graef AS, Gonzalez SS, Baca VR, et al. High serum prolactin levels in asymptomatic HIV-infected patients and in patients with acquired immunodeficiency syndrome. Clin Immunol Immunopathol 1994;72: 390-393.

23 Knoferl MW, Angele MK, Ayala A, et al. Insight into the mechanism by which metoclopramide improves immune functions after trauma-hemorrhage. Am J Physiol Cell Physiol 2000;279:C72-80.

24 Zellweger R, Zhu XH, Wichmann MW, et al. Prolactin administration following hemorrhagic shock improves macrophage cytokine release capacity and decreases mortality from subsequent sepsis. J Immunol 1996; 157:5748-5754.

25 Corbacho AM, Valacchi G, Kubala L, et al. Tissuespecific gene expression of prolactin receptor in the acute phase response induced by lipopolysaccharides. Am J Physiol (Endocrinol Metab) 2004;287:E750-E757.

26 Bernton EW, Meltzer MS, Holaday JW. Suppression of macrophage activation and T-lymphocyte function in hypoprolactinemic mice. Science 1988;239:401-404.

27 Meli R, Raso GM, Bentivoglio C, et al. Recombinant human prolactin induces protection against Salmonella typhimurium infection in the mouse: role of nitric oxide. Immunopharmacology 1996;34:1-7.

28 Tangbanluekal L, Robinette CL. Prolactin mediates estradiol-induced inflammation in the lateral prostate of Wistar rats. Endocrinology 1993;132:2407-2416.

29 Olson KK, Townson DH. Prolactin-induced expression of intercellular adhesion molecule-1 and the accumulation of monocytes/macrophages during regression of the rat corpus luteum. Biol Reprod 2000;62:1571-1578.

30 Meli R, Gualillo O, Raso GM, et al. Further evidence for the involvement of prolactin in the inflammatory response. Life Sci 1993;53:PL105-10.

31 Canbay E, Norman M, Kilic E, et al. Prolactin stimulates the JAK2 and focal adhesion kinase pathways in human breast carcinoma T47-D cells. Biochem J 1997;324(Part 1):231-236.

32 Ryu H, Lee JH, Kim KS, et al. Regulation of neutrophil adhesion by pituitary growth hormone accompanies tyrosine phosphorylation of Jak2, p125FAK, and paxillin. J Immunol 2000;165:2116-2123.

33 Murdoch C, Finn A. Chemokine receptors and their role in inflammation and infectious diseases. Blood 2000;95:3032-3043.

34 Corbacho AM, Macotela Y, Nava G, et al. Human umbilical vein endothelial cells express multiple prolactin isoforms. J Endocrinol 2000;166:53-62.

35 Shimizu Y, Newman W, Gopal TV, et al. Four molecular pathways of $\mathrm{T}$ cell adhesion to endothelial cells: roles of LFA-1, VCAM-1, and ELAM-1 and changes in pathway hierarchy under different activation conditions. J Cell Biol 1991;113:1203-1212.

36 Ager A. Transedothelial migration of lymphocytes in vitro. In: Lefkovits I (ed). Immunology Methods Manual. Academic Press: San Diego, 1997.

37 Corbacho AM, Macotela Y, Nava G, et al. Cytokine induction of prolactin receptors mediates prolactin inhibition of nitric oxide synthesis in pulmonary fibroblasts. FEBS Lett 2003;544:171-175.

38 Kelley KDR. Growth hormone and prolactin as natural antagonists of glucocorticoids in immunoregulation. In: Plotnikoff N, Murgo A, Faith R, Wybran J (eds). Stress and Immunity. CRC Press: Boca Raton, FL, 1991, pp 433-452.
39 Krishnan N, Thellin O, Buckley DJ, et al. Prolactin suppresses glucocorticoid-induced thymocyte apoptosis in vivo. Endocrinology 2003;144:2102-2110.

40 Pankonin G, Reipert B, Ager A. Interactions between interleukin-2-activated lymphocytes and vascular endothelium: binding to and migration across specialized and non-specialized endothelia. Immunology 1992;77:51-60.

41 Clark R. The somatogenic hormones and insulin-like growth factor-1: stimulators of lymphopoiesis and immune function. Endocr Rev 1997;18:157-179.

42 Fuh G, Colosi P, Wood WI, et al. Mechanism-based design of prolactin receptor antagonists. J Biol Chem 1993;268:5376-5381.

43 Ortega E, Forner MA, Barriga C. Exercise-induced stimulation of murine macrophage chemotaxis: role of corticosterone and prolactin as mediators. J Physiol 1997;498(Part 3):729-734.

44 Rot A, von Andrian UH. Chemokines in innate and adaptive host defense: basic chemokinese grammar for immune cells. Annu Rev Immunol 2004;22: 891-928.

45 Patel L, Charlton SJ, Chambers JK, et al. Expression and functional analysis of chemokine receptors in human peripheral blood leukocyte populations. Cytokine 2001;14:27-36.

46 Loetscher M, Gerber B, Loetscher P, et al. Chemokine receptor specific for IP10 and mig: structure, function, and expression in activated T-lymphocytes. J Exp Med 1996;184:963-969.

47 Marx N, Mach F, Sauty A, et al. Peroxisome proliferator-activated receptor-gamma activators inhibit IFN-gamma-induced expression of the $\mathrm{T}$ cell-active CXC chemokines IP-10, Mig, and I-TAC in human endothelial cells. J Immunol 2000;164:6503-6508.

48 Mohan K, Ding Z, Hanly J, et al. IFN-gamma-inducible $\mathrm{T}$ cell alpha chemoattractant is a potent stimulator of normal human blood $\mathrm{T}$ lymphocyte transendothelial migration: differential regulation by IFN-gamma and TNF-alpha. J Immunol 2002;168:6420-6428.

49 Piali L, Weber C, LaRosa G, et al. The chemokine receptor CXCR3 mediates rapid and shear-resistant adhesion-induction of effector $\mathrm{T}$ lymphocytes by the chemokines IP10 and Mig. Eur J Immunol 1998;28: 961-972.

50 Rose DM, Liu S, Woodside DG, et al. Paxillin binding to the alpha 4 integrin subunit stimulates LFA-1 (integrin alpha $\mathrm{L}$ beta 2)-dependent $\mathrm{T}$ cell migration by augmenting the activation of focal adhesion kinase/ proline-rich tyrosine kinase-2. J Immunol 2003;170: 5912-5918.

51 Imhof BA, Aurrand-Lions M. Adhesion mechanisms regulating the migration of monocytes. Nat Rev Immunol 2004;4:432-444.

52 Turner CE. Paxillin and focal adhesion signalling. Nat Cell Biol 2000;2:E231-E236.

53 Nakamura K, Yano $\mathrm{H}$, Uchida $\mathrm{H}$, et al. Tyrosine phosphorylation of paxillin alpha is involved in temporospatial regulation of paxillin-containing focal adhesion formation and F-actin organization in motile cells. J Biol Chem 2000;275:27155-27164.

54 Matera L, Cutufia M, Geuna M, et al. Prolactin is an autocrine growth factor for the Jurkat human T-leukemic cell line. J Neuroimmunol 1997;79:12-21.

55 DaSilva L, Rui H, Erwin RA, et al. Prolactin recruits STAT1, STAT3 and STAT5 independent of conserved receptor tyrosines TYR402, TYR479, TYR515 and TYR580. Mol Cell Endocrinol 1996;117:131-140. 
56 Van de Kar LD, Blair ML. Forebrain pathways mediating stress-induced hormone secretion. Front Neuroendocrinol 1999;20:1-48.

57 Sabharwal P, Glaser R, Lafuse WP, et al. Prolactin synthesized and secreted by human peripheral blood mononuclear cells: an autocrine growth factor for lymphoproliferation. Proc Natl Acad Sci USA 1992; 89:7713-7716.
58 Clapp C, Lopez-Gomez FJ, Nava G, et al. Expression of prolactin mRNA and of prolactin-like proteins in endothelial cells: evidence for autocrine effects. J Endocrinol 1998;158:137-144.

59 Ochoa A, Montes de Oca P, Rivera JC, et al. Expression of prolactin gene and secretion of prolactin by rat retinal capillary endothelial cells. Invest Ophthalmol Vis Sci 2001;42:1639-1645. 